\title{
Boryl-Assisted Hydrogenolysis of a Nickel-Methyl bond
}

\author{
Natalia Curado, ${ }^{a}$ Celia Maya, ${ }^{a}$ Joaquín López-Serrano* ${ }^{* a}$ and Amor Rodríguez*a
}

A stable Nickel(II) methyl complex containing a diphosphinoboryl (PBP) pincer ligand is described. Mechanistic studies on the hydrogenolysis of the Ni-Me bond suggest a metal ligand cooperation mechanism that involves the intermediacy of a $\sigma$ B-H Ni(0) species that further undergoes B-H oxidative addition to form a $\mathrm{Ni}$ (II) hydride complex.

Transition metal complexes containing pincer ligands are used to support catalysts in a large variety of processes due to their potential to promote unusual chemical transformations. ${ }^{1}$ In these systems the electronic and steric properties can be easily modulated by varying the ligand architecture. Therefore, correlating their structure and chemical reactivity is crucial in the design of novel catalytic systems. Recently, Nozaki, Yamashita and Hill succeeded in the synthesis of tridentate ligands incorporating boron on the central atom (PBP) and in the coordination of these to transition metals. ${ }^{2}$ The interest in this class of ligands lies in their potential to display novel reactivity due to the strong $\sigma$-donor ability and high trans influence exerted by the boryl moiety. ${ }^{3}$ Recently, Peters and co-workers reported the addition of $\mathrm{H}_{2}$ across a metal-boryl bond mediated by a PBP pincer cobalt complex. ${ }^{4}$ The ability of boron to act as a 'hydride shuttle' operating in a cooperative manner with the metal, via $\mathrm{B}-\mathrm{H}$ bond activation, renders the process reversible. Such reactivity has shown to be useful for interesting catalytic applications. In light of these precedents, we became interested in investigating the possible non-innocent character of the boryl-fragment for the development of further catalyst systems that utilize this strategy. Nickel based catalysts represent an excellent alternative for precious metals catalysts and have proven to be versatile in several catalytic transformations. ${ }^{5}$ In this contribution we report the synthesis and structural characterization of the first PBP pincer nickel complexes. ${ }^{6}$ Moreover, we will prove the prominent role of the nickel-boryl moiety in the mechanism of hydrogenolysis of a nickel-methyl bond.

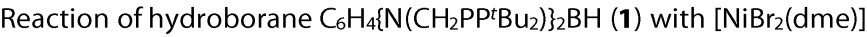
(dme $=1,2$ - dimethoxyethane) in the presence of NEt3 allowed the formation of complex $\mathbf{2}$ as an air and moisture sensitive yellow solid in $65 \%$ yield (Scheme 1). The equivalence of both phosphorous nuclei was confirmed by a singlet resonance at $85 \mathrm{ppm}$ in the ${ }^{31} \mathrm{P}\left\{{ }^{1} \mathrm{H}\right\} \mathrm{NMR}$ spectra while, in the ${ }^{1} \mathrm{H}$ and ${ }^{13} \mathrm{C}$ NMR spectra, the methyl groups of the ${ }^{t} \mathrm{Bu}$ substituents appear as virtual triplets consistent with a squareplanar geometry. The ${ }^{11} \mathrm{~B}\left\{{ }^{1} \mathrm{H}\right\}$ spectrum features one broad resonance at 39 ppm assigned to a coordinated $\sigma$-boryl ligand.?

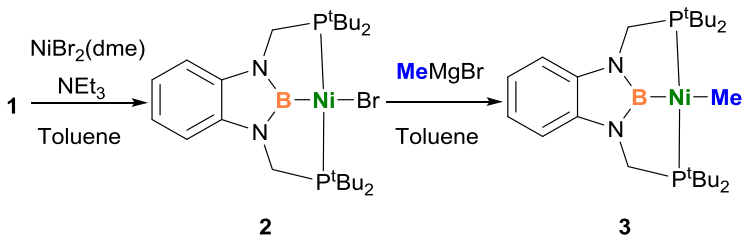

Scheme 1 Synthesis of complexes $\mathbf{2}$ and $\mathbf{3}$.

Treatment of $\mathbf{2}$ with MeMgBr generates $\mathbf{3}$ in $83 \%$ yields. Similarly to $\mathbf{2}$, complex $\mathbf{3}$ proved to be very sensitive and decomposed readily when exposed to air or moisture. In the ${ }^{1} \mathrm{H}$ NMR spectrum, the most characteristic resonance is a triplet centred at $0.15 \mathrm{ppm}\left({ }^{3} \mathrm{~J}_{\mathrm{P}-\mathrm{H}}=5.9 \mathrm{~Hz}\right)$ assigned to the methyl group and the corresponding carbon signal appears as a triplet at $-8.94 \mathrm{ppm}\left({ }^{2} J_{\mathrm{C}-\mathrm{p}}=12.9 \mathrm{~Hz}\right)$ in the ${ }^{13} \mathrm{C}\left\{{ }^{1} \mathrm{H}\right\}$ spectrum. The phosphorous resonance at $97 \mathrm{ppm}$ is shifted downfield relative to 2 in the ${ }^{31} \mathrm{P}\left\{{ }^{1} \mathrm{H}\right\}$ spectrum. Finally, the ${ }^{11} \mathrm{~B}\left\{{ }^{1} \mathrm{H}\right\}$ spectrum features a broad signal at $46 \mathrm{ppm}$, consistent with a metal bound boron centre. The solid state structures of $\mathbf{2}$ and $\mathbf{3}$ were borne out by X-ray diffraction analysis. Both complexes feature a slightly distorted square-planar geometry at nickel (Figure 1). The Ni-B bond lengths (1.900 (3) and 1.928 (2) Å in $\mathbf{2}$ and 3, respectively) are close in value to those reported for related nickel-boryl complexes.? Likewise, the $\mathrm{Ni}-\mathrm{Br}(2.3700$ (3) Å) (2) and $\mathrm{Ni}-\mathrm{C}$ bond lengths (2.059 (2) $\AA$ ) (3) are slightly longer than other reported for analogous tridentate diphosphine aryl pincer 
derivatives, ${ }^{8}$ which can be attributed to the strong trans influence of the boryl ligand. It is worth mentioning that nickel boryl complexes are very rare $^{7}$ and complex 3 constitutes the first example to date of a stable nickel species containing both an alkyl and a boryl group. The geometry imposed by the PBP ligand forces the boryl and methyl groups to be mutually trans thwarting the reductive elimination of the corresponding methylborane. Accordingly, solutions of $\mathbf{3}$ can be heated to $70^{\circ} \mathrm{C}$ for long periods of time with no appreciable signs of decomposition as indicated by ${ }^{31} \mathrm{P}$ spectroscopy. ${ }^{9}$
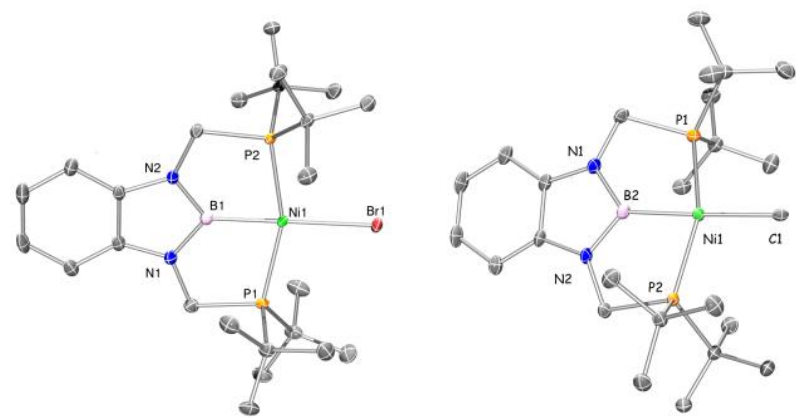

Figure 1. Thermal ellipsoids plots (50\%) for $\mathbf{2}$ (left) and $\mathbf{3}$ (right). Hydrogens are omitted for clarity. Selected bond distances lengths? $(\AA)$ and angles $\left({ }^{\circ}\right)$ : Ni-B = 1.900 (3) (2), 1.928 (2) (3); Ni-Br= 2.370 (3) (2); Ni-C = 2.059 (2) (3); $\mathrm{P}-\mathrm{Ni}-\mathrm{P}=157.58$ (2) (2), 155.41 (2) (3); $\mathrm{B}-\mathrm{Ni}-\mathrm{Br}=178.35$ (8) (2); $\mathrm{B}-\mathrm{Ni}-\mathrm{C}=176.88$ (7) (3).

In order to gain more information about the behavior of this nickelboryl species we decided to explore its reactivity toward dihydrogen, since examples of homogenous hydrogenation reactions catalyzed by nickel complexes are very limited. ${ }^{10}$ We were thus intrigued to learn whether, in our case, the heterolytic cleavage of $\mathrm{H}_{2}$ is facilitated by the presence of the boryl moiety through a mechanism involving metalligand cooperation. Thus, exposure of 3 to $\mathrm{H}_{2}$ (2 bar) at $70^{\circ} \mathrm{C}$ cleanly generates nickel hydride complex 4 and methane (Scheme 2). Complex $\mathbf{4}$ was characterized by spectroscopy (NMR, IR) and analytical methods. The ${ }^{1} \mathrm{H}$ NMR spectra of $4\left(\mathrm{C}_{6} \mathrm{D}_{6}\right)$ shows a characteristic triplet hydride resonance at $-1.72 \mathrm{ppm}\left({ }^{2} \mathrm{JP}_{\mathrm{P}-\mathrm{H}}=33.5 \mathrm{~Hz}\right)$ and the IR spectrum exhibits a $\mathrm{Ni}-\mathrm{H}$ stretch at $1655 \mathrm{~cm}^{-1}$. In the ${ }^{11} \mathrm{~B}\left\{{ }^{1} \mathrm{H}\right\}$ spectrum a broad signal at $48 \mathrm{ppm}$ is consistent with a $\mathrm{B}-\mathrm{Ni}$ bond. Replacement of $\mathrm{H}_{2}$ with $\mathrm{D}_{2}$ gives the corresponding isotopologue $[(\mathrm{PBP}) \mathrm{NiD}]$ and $\mathrm{CDH}_{3}$ as the only deuterated species.

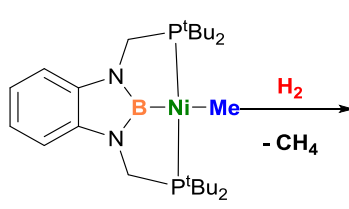

3

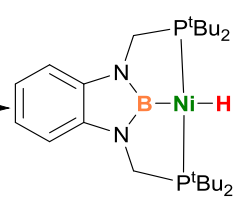

4
Scheme 2 Reactivity of $\mathbf{3}$ towards $\mathrm{H}_{2}$.

Monitoring the reaction by ${ }^{1} \mathrm{H}$ and ${ }^{31} \mathrm{P}$ NMR spectroscopy, in the range -50 to $70^{\circ} \mathrm{C}$, did not provide evidence of intermediates; subsequently the mechanism of this reaction was investigated via computational methods. DFT calculations located a transition state (TS1) for dihydrogen splitting at 3 with relative energy $\Delta E^{\ddagger}=22.2 \mathrm{kcal} \cdot \mathrm{mol}^{-1}$ (zero-point corrected energy in benzene; Figure 2). ${ }^{11} \mathrm{~A}$ minimum for the corresponding $\eta^{2}-\mathrm{H}_{2}$ adduct could not be located, however the $\eta^{2}$ coordination mode of $\mathrm{H}_{2}$ could be demonstrated for a model system, in which the tBu groups on the $\mathrm{P}$ atoms were replaced by $\mathrm{Me}\left(\mathbf{3}_{\mathbf{M e}} \cdot \mathbf{H}_{\mathbf{2}}\right)$ (see ESI). The species resulting from $\mathrm{H}-\mathrm{H}$ cleavage, $\mathbf{5} \cdot \mathbf{C H}_{\mathbf{4}}$, features a $\mathrm{B}-$ $\mathrm{H}$ borane group coordinated in a $\eta^{2}$ fashion to $\mathrm{Ni}$ and $\sigma$-bonded methane. $\eta^{2} \mathrm{~B}-\mathrm{H}$ coordination is reflected in the $\mathrm{Ni}-\mathrm{B}$ and $\mathrm{Ni}-\mathrm{H}$ distances of 1.99 and $1.81 \AA$, respectively, and in the elongation of the calculated $\mathrm{B}-\mathrm{H}$ distance from $1.18 \AA$ in the free ligand to $1.25 \AA$ in this intermediate (See ESI). $\mathrm{H}-\mathrm{H}$ cleavage is not reversible according to the calculated reverse energy barrier $\left(\Delta E^{\ddagger}=32.8 \mathrm{kcal} \cdot \mathrm{mol}^{-1}\right)$, in agreement with the reactivity with $D_{2}$ (vide supra). After methane loss from $\mathbf{5} \cdot \mathbf{C H}_{4}$, $\mathrm{B}-\mathrm{H}$ oxidative addition at $\mathbf{5}$ gives $\mathrm{Ni}$ (II)-hydride $\mathbf{4}$ through a transition state (TS2) with a relative energy from $\mathbf{5}$ of $21.5 \mathrm{kcal} \cdot \mathrm{mol}^{-1}$. The calculations also predict that $\mathrm{Ni}(\mathrm{II})$ hydride $\mathbf{4}$ is more stable than $\mathrm{Ni}(0)$ $\sigma$-borane $\mathbf{5}$ by ca. $10 \mathrm{kcal} \cdot \mathrm{mol}^{-1}$.

To measure the kinetics of the hydrogenolysis process, complex $\mathbf{3}$ was heated with 1 bar of $\mathrm{H}_{2}$ at different temperatures ranging from 65 to $75^{\circ} \mathrm{C}$. On bases of the Eyring equation, the measured activation enthalpy $\left(\Delta H^{\ddagger}\right)$ and entropy $\left(\Delta S^{\ddagger}\right)$ values are $14.4 \pm 1.2 \mathrm{kcal} \mathrm{mol}^{-1}$ and $27.6 \pm 0.4 \mathrm{cal} \mathrm{mol}^{-1} \mathrm{~K}^{-1}$, respectively, which corresponds to a Free Energy of activation $\left(\Delta G^{\ddagger}\right)$ at $298 \mathrm{~K}$ of $22.7 \pm 1.3 \mathrm{kcal} \mathrm{mol}^{-1}$. These values are in good agreement with those calculated. (See ESI). Use of $D_{2}$ resulted in a normal kinetic isotopic effect $K_{\mathrm{H}} / K_{\mathrm{D}}$ of 1.9 at $70{ }^{\circ} \mathrm{C}$, which indicates that a $\mathrm{H}-\mathrm{H}$ cleavage process is involved in the ratedetermining step.

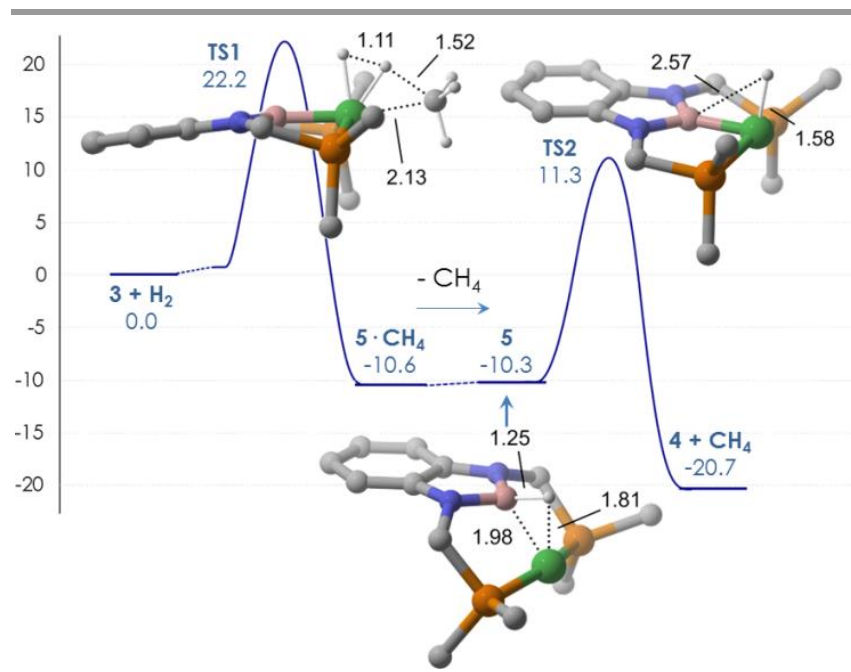

Figure 2. DFT calculated energy profile $\left(\mathrm{kcal} \cdot \mathrm{mol}^{-1}\right.$, Zero Point-corrected Energies in benzene) of the hydrogenolysis of the $\mathrm{Ni}-\mathrm{CH}_{3}$ bond of 3 .

Support for our mechanistic proposal was obtained by the characterization by NMR spectroscopy of a $\left[\left(\eta^{2}-\mathrm{B}-\mathrm{H}\right) \mathrm{Ni}(0)\right]$ derivative, $\mathbf{5 \cdot c o d}$, from the reaction of $\mathbf{4}$ with 1,5-cyclooctadiene (cod). ${ }^{12}$ Monitoring of the reaction by NMR spectroscopy confirmed the formation of a new species and the presence of the starting material. The ${ }^{31} \mathrm{P}\left\{{ }^{1} \mathrm{H}\right\}$ spectrum shows three peaks; one of them ( $\delta 123 \mathrm{ppm}$ ) corresponds to complex 4. The other two peaks appear at $10 \mathrm{ppm}$ and 76 ppm suggesting different environments for the two phosphorous nuclei. One of the signals is very close to that observed for the free ligand $\left(\delta^{31} \mathrm{p}=16 \mathrm{ppm}\right)$ while the other appears at significantly lower field, indicative of coordination to the metal atom. ${ }^{13}$ The ${ }^{1} \mathrm{H}$ NMR spectra reveal the presence of coordinated cod in the new species and show a broad resonance at $-4.7 \mathrm{ppm}$, which integrates to one proton and sharpens upon ${ }^{11} \mathrm{~B}$ decoupling. This resonance is assigned to the 
$\mathrm{H}$ atom of a $\mathrm{B}-\mathrm{H}$ bond coordinated to nickel. ${ }^{14}$ The ${ }^{11} \mathrm{~B}$ spectrum exhibits two resonances; one at $48 \mathrm{ppm}$, that corresponds to complex 4 and a new peak at 31 ppm that we assign to the new species $\mathbf{5} \cdot \mathbf{c o d}$. The methyl protons of the ${ }^{\mathrm{t}} \mathrm{Bu}$ groups and the bridging $\mathrm{CH}_{2}$ protons for new species $\mathbf{5 \cdot c o d}$ resonate as two set of doublets at 1.08 and 1.11 $\mathrm{ppm}$, and at 3.38 and $4.42 \mathrm{ppm}$ respectively. These doublets collapse into two singlets upon ${ }^{31} \mathrm{P}$ decoupling. Off-diagonal peaks in $2 \mathrm{D}$ NOESY/Exchange Spectroscopy (EXSY) experiments confirmed the exchange between both $\mathrm{CH}_{2}$ groups and between the aromatic $\mathrm{CH}$ protons, suggesting that a fluxional process exchanges both phosphorous atoms (Scheme 3). Overall, these spectroscopic data are consistent with the formation of a $\left[\left(\eta^{2}-\mathrm{B}-\mathrm{H}\right) \mathrm{Ni}(0)\right]$ species $\mathbf{5} \cdot \mathbf{c o d}$ from complex 4 in which the hydride ligand has migrated to the boron centre (Scheme 3) ${ }^{15,16}$ Nevertheless, 5·cod slowly evolves into $\mathrm{Ni}(\mathrm{cod})_{2}$ with the concomitant loss of the free PBP ligand along with the formation of several unidentified products (See ESI).

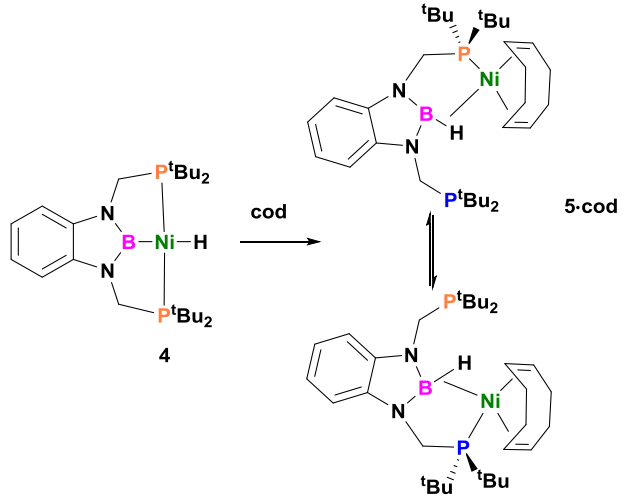

Scheme 3 Synthesis of $\eta^{2}-(B-H) N i(0)$ complex $\mathbf{5} \cdot \operatorname{cod}$.

Details of hydrogen cleavage at $\mathbf{3}$ were addressed by analysing the centroids of the localized orbitals ${ }^{17}$ of the model system $\mathbf{3}_{\mathbf{M e}}+\mathrm{H}_{2}$ at various points along the reaction coordinate, as described by Vidossich and Lledós. ${ }^{18}$ According to this study $\eta^{2}$ coordination of $\mathrm{H}_{2}$ to $\mathbf{3}_{\mathrm{Me}}$ does not perturb the electronic structure around $\mathrm{Ni}$, which remains covalently bonded to the methyl ligand and boron atom and through one dative bond (polarized away from $\mathrm{Ni}$ ) to each phosphorous of the molecule. The presence of four localized orbitals on the nickel atom is consistent with the +2 oxidation state. At the transition state TS1 the symmetry of the $\mathrm{H}-\mathrm{H}$ bond is broken, as indicated by the displacement of the centroid of the $\mathrm{H}-\mathrm{H}$ localized orbital towards one of the hydrogen atoms, to give hydride-like $\left(\mathrm{H}^{-}\right)$and proton-like $\left(\mathrm{H}^{+}\right)$atoms (Figure 3); even though the $\mathrm{H}-\mathrm{H}$ distance is still $1.11 \AA \AA$. At the same time the centroid of the $\mathrm{Ni}-\mathrm{B}$ orbital is displaced towards $\mathrm{Ni}$, so that the orbital eventually becomes metal centred. Also, the centroid of the $\mathrm{Ni}-\mathrm{C}$ orbital is displaced from the line connecting the two atoms towards the $\mathrm{H}^{+}$. As the molecule further evolves along the intrinsic reaction coordinate (IRC), ${ }^{19}$ two new $\mathrm{B}-\mathrm{H}$, and $\mathrm{C}-\mathrm{H}$ bonding orbitals form, the former having its origin in the $\mathrm{H} H$ bond and the latter in the $\mathrm{Ni}-\mathrm{C}$ bond. Thus, the Lewis-acidic boron accepts $\mathrm{H}^{-20}$ whereas the electrophilic $\mathrm{Ni}(\mathrm{II})$ does not form a new bond with $\mathrm{H}^{+}$, at variance with $\mathrm{Ni}(0)$ complexes by Peters, ${ }^{4}$ instead it acts as an electron sink ${ }^{21}$ for the $\mathrm{Ni}-\mathrm{B}$ bond. Therefore intermediate $\mathbf{5}_{\mathbf{M e}} \cdot \mathbf{C H}_{\mathbf{4}}$ has five Ni-localized orbitals and forms one dative bond with each phosphorous, as expected for $\mathrm{Ni}(0)$.

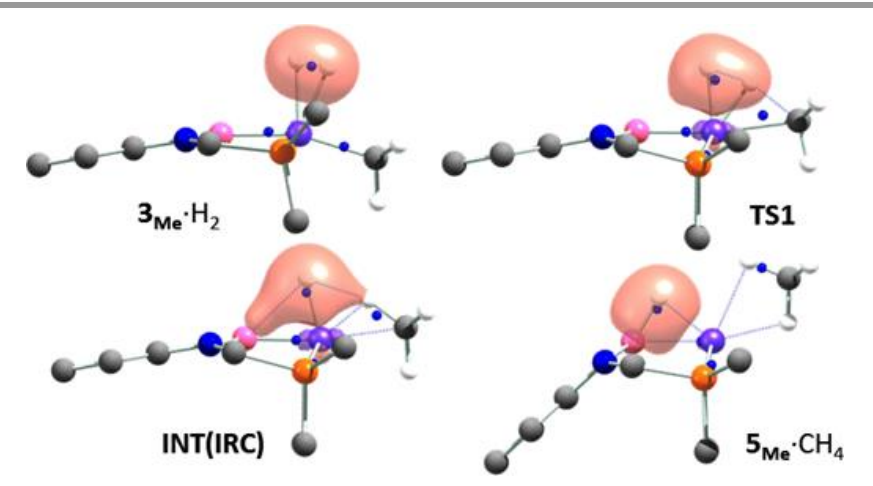

Figure 3. Evolution of the $\mathrm{H}-\mathrm{H}$ localized orbital along the reaction coordinate. Blue dots represent the centroids of the $\mathrm{H}-\mathrm{H}, \mathrm{Ni}-\mathrm{B}$ and $\mathrm{N}-\mathrm{Me}$ orbitals. The species labelled INT corresponds to a point along the intrinsic reaction coordinate between TS1 and $5_{\mathrm{Me}} \cdot \mathrm{CH}_{4}$

In conclusion, the diphosphino-boryl nickel pincer complexes of type [(PBP)NiX] (X = Br (2), Me (3), H (4)) have been described. Theoretical calculations on the hydrogenation reaction of $\mathbf{3}$ evince a new mechanism for $\mathrm{H}-\mathrm{H}$ activation that involves a cooperative role for boron and $\mathrm{Ni}(\mathrm{II})$. The resulting $\mathrm{Ni}(0) \quad \sigma$-borane intermediate $\mathbf{5}$ experiences further oxidative addition of the $\mathrm{B}-\mathrm{H}$ bond to form the hydride complex 4. Experimental evidence of intermediate 5 was provided by NMR spectroscopy analysis of the reaction of 4 with 1,5cyclooctadiene. The implications of this metal-ligand cooperativity in the design of homogeneous nickel hydrogenation catalysts are currently being studied in our research group.

\section{Notes and references}

a Instituto de Investigaciones Químicas-Departamento de Química Inorgánica. Universidad de Sevilla-Consejo Superior de Investigaciones Científicas. Avenida Américo Vespucio 49, 41092 Sevilla, Spain. Fax: (+) 34-954460565; E-mail: joaquin.lopez@,iiq.csic.es; marodriguez@,iiq.csic.es

$\dagger$ Financial support (FEDER contribution and Subprograma Ramón y Cajal) from the Spanish Ministry of Economy and Competitiveness (Projects CTQ2013-45011) and the Junta de Andalucía (Project FQM$2126)$ is gratefully acknowledged. The use of computational facilities of the CSIC (Cluster Trueno) and the Center of Supercomputing of Galicia (CESGA) are thankfully acknowledged.

Electronic supplementary information (ESI) available: Experimental procedures and characterization data for all new compounds described herein along with CIF files for 2 and 3. CCDC 1011941 and 1011942. For ESI and crystallographic data in CIF or other electronic format see DOI: 10.1039/c000000x/

1 D. Morales-Morales, C. Jensen, The Chemistry of Pincer Compounds, Morales-Morales, D.; Jensen, C., Eds.; Elsevier Science: Amsterdam, 2007. b) G. van Koten and D. Milstein, Top Organometal Chem. 2013, vol. 40 .

2 a) Y. Segawa, M. Yamashita and K. Nozaki, J. Am. Chem. Soc., 2009, 131, 9201. b) Y. Segawa, M. Yamashita and K. Nozaki, Organometallics 2009, 28, 6234. c) M. Hasegawa, Y. Segawa, M. Yamashita and K. Nozaki, Angew. Chem. Int. Ed. 2012, 51, 6956. d) H. Ogawa and M. Yamashita, Dalton Trans. 2013, 42, 625. e) T. Miyada and M. Yamashita, Organometallics 2013, 32, 5281. f) A. F. Hill, S. B. Lee, J. Park, R. Shang, and A. C. Willis, Organometallics 2010, 29, 5661. 
3 J. Zhu, Z. Lin and T. B. Marder, Inorg. Chem. 2005, 44, 9384.

4 T-P. Lin and J. C. Peters, J. Am. Chem. Soc., 2013, 135, 15310.

5 S. Z. Tasker, E. A. Standley and T. F. Jamison, Nature, 2014, 509, 299.

6 While this manuscript was under revision, Jonas C. Peters and Tzu-Pin Lin, reported a very related work. See: J. C. Peters and T.-P. Lin J. Am. Chem. Soc. 2014, DOI: 10.1021/ja504667f.

7 D. Adhikari, J. C. Huffman and D. J. Mindiola, Chem. Commun., 2007, 4489.

8 a) T. J. Schmeier, N. Hazari, C. D. Incarvitoa and J. A. Raskatovb, Chem. Commun., 2011, 1824. b) A. Castonguay, A. L. Beauchamp and D. Zargarian, Organometallics 2008, 27, 5723. c) A. B. Salah and D. Zargarian, Dalton Trans. 2011, 40, 8977.

9 Partial decomposition (ca $40 \%$ ) of complex 4 is observed after heating toluene solutions at $100^{\circ} \mathrm{C}$ during 12 hours.

10 a) I. M. Angulo, A. M. Kluwer and E. Bouwman Chem. Commun., 1998, 2689. b) I. M. Angulo, S. M. Lok, V. F. Q. Norambuena, M. Lutz, A. L. Spek, E. Bouwman J. Mol. Catal. A, Chem. 2002, 187, 55. c) I. M. Angulo, E. Bouwman, R. van Gorkum, S. M. Lok, M. Lutz, A. L. Spek J. Mol. Catal. A, Chem. 2003, 202, 97. d) Y. Hamada, Y. Koseki, T. Fujii, T. Maeda, T. Hibino and K. Makino Chem. Commun., 2008, 6206. e) T. Hibino, K. Makino, T. Sugiyama, and Y. Hamada ChemCatChem. 2009, 1, 237. f) K. V. Vasudevan, B. L. Scott and S. K. Hanson Eur. J. Inorg. Chem. 2012, 4898. g) W. Hill Harman and J. C. Peters J. Am. Chem. Soc. 2012, 134, 5080. h) J. Wu, J. W. Faller, N. Hazari and T. J. Schmeier Organometallics 2012, 31, 806. i) T. J. Mooibroek, E. C. M. Wenker, W. Smit, I. Mutikainen, M. Lutz and E. Bouwman, Inorg. Chem. 2013, 52, 8190.

11 The calculations were carried out at the PBE0, 6-31g(d,p) + SDD level of theory: Solvent (benzene) effects were included with the SMD continuum model; The Gaussian 09 package was used: Gaussian 09, Revision A.02, M. J. Frisch et al.; See the SI for the full citations.

12 a) G. Alcaraz and S. Sabo-Etienne, Coord. Chem. Rev., 2008, 252, 2395. b) K. K. Pandey, Coord. Chem. Rev., 2009, 253, 37.

13 O. Kühl, Phosphoros-31 NMR Spectroscopy: A Concise Introduction for the Synthetic Organic and Organometallic Chemist, SpringerVerlag, Berlin, Heidelberg, 2008.

14 For the only example of $\sigma$-borane $\mathrm{Ni}(0)$ complex fully characterized see: M. G. Crestani, M. Muñoz-Hernández, A. Arévalo, A. AcostaRamírez and J. J. García, J. Am. Chem. Soc., 2005, 127, 18066.

15 Recently Hill and co-workers described the isolation of Ru and Os $\sigma$ borane complexes employing the ${ }^{\mathrm{Ph} 2} \mathrm{PBHP}$ ligand. A. F. Hill, S. B. Lee, J. Park, R. Shang and A. C. Willis, Organometallics 2014, 33, 1977.

16 For a similar Ru complex see also: Y. Gloaguen, G. Alcaraz, A. S. Petit, E. Clot, Y. Coppel, L.Vendier and S. Sabo-Etienne, J. Am. Chem. Soc., 2011, 133, 17232.

17 The Pipek-Mezey localization scheme was used: J. Pipek, P. G. Mezey, J. Chem. Phys., 1989, 90, 4916.

18 P. Vidossich, A. Lledós, Dalton Trans., 2014, 43, 11145.

19 K. Fukui, Acc. Chem. Res., 1981, 14, 363.

20 On the contrary, in some cases the $\mathrm{N}$-amido of (PNP)Ni(II) fragments are likely to promote $\mathrm{H}-\mathrm{H}$ or $\mathrm{C}-\mathrm{H}$ activation by acting as internal bases: a) T. He, N. P. Tsvetkov, J. G. Andino, X. Gao, B. C. Fullmer, K. G. Caulton, J. Am. Chem. Soc., 2010, 132, 910. b) L.-C. Liang, P.S. Chien, Y.-L. Huang, J. Am. Chem. Soc., 2006, 128, 15562.
21 Such a role has been proposed for $\mathrm{Ni}$ in [NiFe]-hydrogenases: $\mathrm{C}$. Tard, C. J. Pickett, Chem. Rev., 2009, 109, 2245. 